\title{
Resilience and Students with Chronic Illness: A Literature Review of Fostering Resilience into the Lives of Students with Chronic Illness
}

\author{
Taunya Wideman-Johnston \\ Ontario Institute for Studies in Education (OISE), University of Toronto \\ 252 Bloor St. W., Toronto M5S 1V5, Canada \\ Tel: 1-519-588-3084Ｅ-mail: taunyarose@yahoo.ca
}

Received: September 20, 2011

Accepted: October 27, $2011 \quad$ Published: December 30, 2011

doi:10.5539/jedp.v1n1p127

URL: http://dx.doi.org/10.5539/jedp.v1n1p127

\begin{abstract}
Students with chronic illness (CI) are being given further prospects to attend traditional school settings. The increasing school enrolment of students with CI provides them the opportunity to participate in the community beyond their involvement with the medical community as a patient. The experiences individuals with $\mathrm{CI}$ encounter affect their day-to-day lives and ability to integrate into society. Research suggests having a CI and developing resilience can aid in coping with the adversity present in the lives of those with CI. This paper examines literature discussing the findings of CI and resiliency, and how nurturing resilience in the education of students with CI is a valuable contribution to fostering student success. The methods to support resilience in students with CI in the classroom are discussed and the positive factors associated with encouraging resilience in education.
\end{abstract}

Keywords: Students, Chronic illness, Resilience, Education, School, Special education

\section{Complexities in Defining Chronic Illness}

Defining chronic illness (CI) continues to be a grey area in both the medical and educational community. There are various vague definitions of CI but there remains an absence of a precise definition of CI. The lack of definition inhibits individuals from being able to understand what the term CI means. Presently, the medical community's definition of chronic illness includes a medical ailment that persists for longer than three months (Duggan, Medway, \& Bunke, 2004). The medical model definition does not capture the complexities of the illnesses and symptoms often associated with CI. The lack of clarification of what a chronic illness is forces individuals to seek out their own meaning for CI and what living with a CI entails. For many individuals with a CI, a chronic illness has neither a beginning nor end, and the hope of being cured is absent (Kralik, 2002).

McCabe and Shaw's (2008) definition of CI does not provide reference to the medical diagnoses and symptoms constituting the numerous chronic illnesses but does lend to the individual and societal implications of living with a CI. For the intentions of this paper, CI is defined as, "a medical condition of extended duration that creates impairment in adaptive behaviour and socially defined roles" (McCabe and Shaw, 2008, p. 74). When elaborating the adaptive issues of having a CI McCabe and Shaw (2008) refer specifically to: communication, day-to-day living, self-care, academic abilities, and motor skills. The social repercussions include: social skills, familial dynamics, school experiences, and relationships with medical and psychological support.

The lack of clarity in defining a CI further contributes to the difficulty in identifying the exact number of students with CI. Research indicates numbers varying between 10-30\% of students have a CI (Asprey and Nash, 2006; Martinez and Ericikan, 2009). Martinez and Ercikan (2009) estimated that within Canada 30\% of school aged children have been diagnosed with a CI. The Canadian Council on Social Development (2006) revealed an approximant half a million children living in Canada have been diagnosed with a CI (Martinez and Ercikan, 2009). Other researches indicate percentages between 10-20\% (Asprey and Nash, 2006). Clearly, the lack of definition for CI impedes researchers' ability to identify precise numbers.

\section{Defining Resilience}

Similar to CI, resilience is another term that does not possess one static meaning but rather offers a magnitude of descriptions (Kralik et al., 2006; Polk, 1997; Maluccio, 2002; Masten and Obradovic, 2006; Oswald, Johnson, \& 
Howard, 2003). Resilience research attempts to identify contributing factors to aid individuals in overcoming challenges while others respond negatively to their conditions (Oswald, Johnson, and Howard, 2003). Resilience is a complex approach that permits individuals to move forward in their life from a crisis or trauma. In order for an individual to become resilient he/she requires an adverse experience to impede their growth (Masten, 2001). Luthar et al. (2000) identified two key components of resilience. The first is an environment with a threat or adversity, and the second is the ability to positively adapt although the development process has been affected.

For the purpose of this paper, resilience is defined as "a positive adaptation of a system during or following significant disturbances" (Cutuli, Herbers, Lafavor, Masten, 2008). Researchers have investigated resilience by pursuing the positive adaptations of individuals who are presently, or have previously experienced adversities that can affect their development. Although resilience refers to the individual, resilience is applicable to many of the systems the individual interacts with (Cutuli et al., 2006; Masten and Obradovic, 2006). Students exist with many different levels of systems including their: internal biological, familial role, social relationships, school context, communities, and within societies (Bronfenbrenner, 1979). Masten (2003) cumulated a list of systems that are present in student's lives including: "learning systems, attachment system, mastery motivation, stress responses, self-regulation systems, family system, school, system, peer system, social and cultural system" (Masten and Obradovic, 2006, p. 22). Furthermore, Masten (2003) stated that resilience can apply to one or many of the systems. To expand the understanding of resilience it is essential to define the system functioning competently, and identify contributing factors that can inhibit or affect the development of that system. By identifying the threats, accommodations can be identified in response to the adversity in the system(s) (Cutuli et al., 2008). A resilient person is one who has adapted their life despite the difficult event(s) that surround him/her. Furthermore, the individual is resilient when despite all of the adversity in their life, he/she is able to adapt in a secure and confident approach with the utilization of differing coping mechanisms. Resilience is not solely about survival, but overcoming and prospering are salient features (Green, 2002; Kralik et al., 2006). Being resilient does not involve an individual remaining in a fixed state but is a transitional approach to adapting to adverse conditions and constantly evolving (Kralik, 2006).

Understanding the complexities of both $\mathrm{CI}$ and resilience is central in addressing the intentions of this paper and will further investigate:

1) How incorporating resilience in the education of students with CI can improve their academic experiences by not only fostering academic achievement but increasing their intrapersonal and interpersonal relations, and coping mechanisms.

2) The applications of resilience in education, and the benefits of connecting resilience to the education of students with CI.

In the lives of students with chronic illness, their chronic illness is the adversity that impacts many levels of their systems development. From McCabe and Shaw's (2008) definition of CI, CI impacts both the individuals' social and adaptive functions which include both their day-to-day life and their roles within society. The presence of a chronic illness is a risk factor that affects the academic of journey of students (Asprey and Nash, 2006; Martinez and Ericikan, 2009; McCabe and Shaw, 2008; Thies, 1999; Wideman-Johnston, 2010). Research investigating how individuals positively develop despite their illness requires individuals to critically examining their life and CI. Contributions to aid resiliency in individuals with $\mathrm{CI}$ include understanding the illness, communication, and self-confidence (Polk, 1997). Resiliency and CI have become interwoven as resilience includes focusing on the strengths of the individual and not dwelling on the negative consequences of the illness (Kralik, van Loon, \& Visentin, 2006).

\subsection{The Presence of Resilience in Education}

Resilience is increasingly being investigated and recognized as an important development for students in the school setting. Researchers have created a definition for "educational resilience" which pertains to "the heightened likelihood of educational success despite personal vulnerabilities and adversities brought about by environmental conditions and experiences" (Wang, Haertel, \& Walberg, 1997, p. 2). Educational resilience is not to be confused as a personality trait or the result of one intervention (Franklin, 2000). Resilience is a complex process that occurs between the student and their environment on continuous basis, working against their adverse life conditions (Luthar, Cicchetti, \& Becker, 2000).

Researchers have identified resilience to be a coping mechanism to aid individuals in learning to adapt and pursue their life despite the unfortunate implications of their illness. Kralik et al. (2006) conducted a study where individuals with CI participated in learning circles facilitated through online communication measures that revealed 3 themes associated with resilience and CI. The identified themes included: "constructions of resilience 
in the illness experience, reconciling and reconstructing, and connecting with others" (2006, p. 7). The first theme of constructing resilience involves the individual having firm self-worth, being able to learn from their experiences, and ultimately being able to adapt with constant perseverance. The second theme of reconstructing relates to the ability of the individuals with $\mathrm{CI}$ to adapt and accept the changes that occur in their life. The third theme of connecting with others entails the value of collaboration. Collaborating with others with CI facilitates a community where individuals with CI can support one another on a continuous basis. In the instance that one individual is not feeling strong others can serve as inspiration. The themes identified with Kralik et al.'s (2006) research reveal how living with a $\mathrm{CI}$ is a complex journey that requires the facilitation of actions that will engage individuals with CI to increase self-worth, adaptability, and the importance of sharing with other individuals with CI.

Shapiro (2002) identified strategies to aid fostering resilience in individuals with CI and their families, suggesting the need for a collaborative effort. Shapiro identifies the need for a clear and comprehensive understanding of what the illness is and the effects of the illness. Shapiro advocates for families to address the skills necessary to address the illness, obstacles the individual with the CI and family will encounter, and potential strategies. Shapiro also proposes open communication and understanding within the family and their roles and a strong foundation for support. The integration of these themes into the family environment will foster stability, respect, hope, and ultimately resilience (Shapiro, 2002).

\section{Supporting Students with CI and Fostering Resilience}

Knowing the importance and striving to meet the "best interests" of students is a shared goal among educators. Establishing how educators meet student "best interests" and the differing needs of all students creates complexity when discussing the attainment of achieving the "best interests" of all students. Stefkovich and Begley (2007) have investigated the numerous meanings associated with student "best interests". Depending on the philosophical or theoretical domain one holds will impact the defining components of attaining student "best interests". Examples of contrary perspectives for attaining student "best interests" entail are, "Philosophy, psychology, critical theory, and case law" (Stefkovich and Begley, 2007, p. 205). In relation to meeting the "best interests" of students with CI, educators need to provide a comfortable school environment where students with $\mathrm{CI}$ are granted the same opportunities and experiences as their healthy peers. As educators, understanding the components of resilience and how resilience interacts with individuals with $\mathrm{CI}$ is crucial for promotion of the "best interests" of students with CI in the classroom setting.

The notion that attending school provides far more benefits than simple academic development is not unknown. Consistent school attendance offers opportunities for peer relationships, support, and contribute to an individual's self-worth (McCabe and Shaw, 2008). Research supports that when examining the needs of students with CI, inclusion with conventional life experiences, such as attending traditional school settings is beneficial for students with CI. Attending school allows students with CI not only to have a role in the medical community but fosters a role within society, further creating a sense of self-worth (Worchel-Prevatt, Heffer, Prevatt, Miner, Young-Saleme, \& Horgan, 1998). The inclusion of students with CI in the traditional classroom setting is not to suggest unique needs of each student do not exist but the importance of providing opportunities for inclusive participation.

Wideman-Johnston (2010) reveals four central themes to be considered in the inclusion of students with CI in the school environment. The four themes include: physical limitations, psychological comparisons, social isolation, and academic implications. The physical limitations pertain to the students physical symptoms related to the illness that continue to affect their experiences. Medications, fatigue, physical pain and restrictions are all examples of the physical effects of chronic illness (Thies, 1999; Wideman-Johnston, 2010). The psychological repercussions among students with CI reveal the constant need to compare themselves to their healthy peers, continuously seeing an imbalance in their capabilities and are unable to relate. The social isolation experienced by students with CI relates to the challenges their illness creates in their abilities to interact socially. Student absenteeism and feelings of discomfort are among the factors contributing to social isolation. The academic implications refer to the constant battle of trying to keep caught up with school lessons and assignments. Students with CI revealed their feelings of existing in a constant cycle of attempting to maintain the same pace as their peers and never catching up (Wideman-Johnston, 2010). Clearly, the inclusion of students with CI is a complex process that requires much thought when implementing accommodations. Without the implementation of accommodations for students with CI the school environment can rapidly become a place where academic, social and peer relationships, and psychological failures transpire (Thies, 1999). Addressing the health and academic needs of students with CI needs to be a priority, and supporting these students by fostering resilience is a valuable process worth integrating into their educational program. 


\subsection{Strategies to Aid Resilience in the Classroom}

In order to incorporate resilience in the school setting, educators need to be provided with the tools and strategies to create resilience among students. Resilience is fostered in the classroom environment through the constant interactions with the teacher and student, and between students. Downey (2008) identified strategies and methods for teachers to provide students with exposure to resilience. Downey's (2008) recommendations stem from four clustered themes, "(a) teacher-student rapport, (b) classroom climate, (c) instructional strategies, and (d) student skills" (p.57). Teacher-student relations pertain to the importance of positive, trusting, open relationships between the student and the teacher. The teacher is often associated with far more than curriculum learning but serves as a role model for students. Teachers are also reliable figures within the students' lives, providing a consistent, stable relationship for students to grow. Students knowing that their teacher cares and has their best interest aids in fostering a positive school environment. It is imperative teachers remember their role as leader for students. Within the teacher-student relationship includes the recognition and possibility for student success despite the adversity present in the students' lives. In the instances of students with CI, teachers should listen to the student and ensure they see the student for who they are as an individual and not the illness itself (Thies, 1999). Teachers need to inspire students to work to their abilities. Providing students with concrete opportunities to set goals and incorporate criteria for the school expectations. Teachers also need to combine school curricula to self-esteem. Students need honest teachers who will provide positive learning opportunities that recognize their uniqueness and abilities by focusing on the strengths of the students to aid in fostering resilience.

The classroom atmosphere is a vital component of the learning experience and is a valuable tool for supporting resilience in students. Important components of the classroom environment fostering resilience in education include: "(a) clear behavioral expectations, (b) conveys to students that they are personally responsible for their success, (c) creates a caring classroom community, and (d) provides opportunities for meaningful student participation" (Downey, 2008, p. 59). Students need to realize their autonomy in creating their own success and their valuable contribution to the classroom and school as a whole. Students recognizing they are each a valuable piece of the puzzle fosters their self-worth and connection with others. The integration of both individual and collective goals visible to all students in the classroom, and having distinct student roles within the class all contribute to creating classroom community. Creating cohesiveness in the classroom has been associated with reducing anxiety, increasing peer relations, and the promotion of a safe, effective classroom environment (Borman and Overman, 2004).

Student absenteeism is often a consequence of students with CI. The frequency of students being absent contributes to their ability to feel they are a valued member of the classroom community (McCabe and Shaw, 2008). The creation of a safe school environment fosters respect for the uniqueness of all students in the class, despite individual differences. Connecting student life stories to their school learning fosters further growth and acceptance among students. Sharing stories that relate to students with CI, having the student with a CI share their story, incorporating chronic illnesses into the health curriculum, bringing in health professionals are relate to providing an open, knowledgeable classroom environment. Facilitating peer learning, tutors, and asking why specific issues are important all contribute to classroom climate and combating student absenteeism. Making use of technology with the use of webcams, email, and distance education programs include students with CI into the classroom.

Utilizing the incorporation of students learning from each other and enabling students to rely on each other are instruction strategies for resilience in the school environment. Students are thus able to create a network of support. Opportunities for cooperative learning in both partner and team groupings builds collaboration in the classroom. Within cooperative learning teachers should provide students with problem-solving, hands-on, and inquiry based curricula. Students are then given the prospects to incorporate numerous explanations and answers (Dunn, 2004; Waxman, Gray, \& Padron, 2004). Cooperative learning allows students to improve their relationships and be exposed to the contributions of the other students in the class.

To promote student abilities educators need to provide students with learning opportunities that are applicable to their lives. Offering students opportunities to improve communication, engage in problem-solving, critical thinking, conflict resolution, and exposure to coping mechanisms are all skills necessary to functioning within society (Brooks, 2006; Reis, Colbert, \& Hebert, 2005; Thomsen, 2002). For students with CI, their experiences are quite different from their healthy classmates. Students with CI have their day-to-day lives filled with medical procedures, medications, doctor and hospital appointments, alternate nutrition requirements, and the physical symptoms and effects of the illness itself (Shui, 2001). Teachers need to account the school curriculum relates to the differing life experiences of the students. Teachers can access resources that promote and form relationships 
with other students with CI to maximize collaboration and a sense of belonging in a community.

\section{Discussion}

The integration of students with CI into the traditional school setting is a multifaceted issue that requires much thought when facilitating their inclusion. Educators can support students with CI not only by meeting their physical and academic needs but by providing them with the opportunity to engage in the cultivation of resilience.

Understanding what a $\mathrm{CI}$ is and the obstacles students with $\mathrm{CI}$ encounter will aid educators in developing educational programs that are unique to students with CI. Furthermore, educators can aid students with CI by supporting the development of resilience to improve their academic experiences, intra- and interpersonal relations, and their abilities to cope with adversity. Research by Kralik (2002) and Shapiro (2002) reveals how resilience improves self-worth, accepting change, and collaboration both among other individuals with $\mathrm{CI}$ and without. Having the skills and a positive self-image to cope with change will aid students with CI in dealing with the physical, psychological, social, and academic implications of having a CI (Wideman-Johnston, 2010).

Living life with a CI means living with much adversity and instability. Students with CI need to be encouraged and provided with opportunities that instill positive growth, stress management, and the ability to adapt. The integration of resilience into the educational setting promotes understanding, self-worth, and efficient communication strategies. Resiliency among individuals with a CI enables them to understand the dynamics of their illness, to communicate effectively, and having improved self-esteem (Polk, 1997).

Research suggests developing resilience in individuals with CI and fostering resilience within the educational setting have both demonstrated to be advantageous by promoting positive self-growth. Further research investigating how to support students with $\mathrm{CI}$ and developing resilience in the educational setting, as well as, identifying direct strategies to promote resilience in students with $\mathrm{CI}$ in the academic setting is needed. What research has demonstrated is the importance of educators providing students with opportunities to develop resilience in the educational setting, and the progression of resilience in individuals with CI. Integrating specific strategies for students with CI that support resilience in the education setting remains an unchartered area of research that requires further investigation. Outlining strategies unique to the experiences of students with CI would be a valuable contribution to providing inclusive education for students with CI.

\section{References}

Asprey, A., \& Nash, T. (2006). The importance of awareness and communication for the inclusion of young people with life limiting and life threatening conditions in mainstream schools and colleges. British Journal of Special Education, 33(1), 10-18. http://dx.doi.org/10.1111/j.1467-8578.2006.00406.x

Borman, G., \& Overman, L. (2004). Academic resilience in mathematics among poor and minority students. Elementary School Journal, 104, 177-197. http://dx.doi.org/10.1086/499748

Bronfenbrenner, U. (1979). The ecology of human development: Experiments by nature and design. Cambridge, MA: Havard University Press.

Brooks, J. (2006). Strengthening resilience in children and youths: Maximizing opportunities through the schools. Children \& Schools, 28, 2, 69-76.

Cutuli, J. J., Herbers, J. E., Lafavor, T. L., \& Masten, A. S. (2008, December). Promoting competence and resilience in the school context. Professional School Counseling, 12(2), 76. [Online] Available: http://go.galegroup.com/ps/i.do?\&amp;id=GALE\%7CA191213587\&amp;v=2.1\&amp;u=utoronto_main\&amp;it $=\& \mathrm{amp} ; \mathrm{p}=\mathrm{AONE} \& \mathrm{amp} ; \mathrm{sw}=\mathrm{w}$

\section{Deveson, A. (2003). Resilience. Crows Nest, Australia: Allen \& Unwin.}

Downey, J. (2008). Recommendations for fostering educational resilience in the classroom. Preventing School Failure, 53(1), 56-64. http://dx.doi.org/10.3200/PSFL.53.1.56-64

Duggan, D. D., Medway, F. J., \& Bunke, V. L. (2004). Training educators to address the needs and issues of students with chronic illnesses: Examining their knowledge, confidence levels, and perceptions. Canadian Journal of Psychology, 19(1/2), 149-165.

Dunn, T. (2004). Enhancing mathematics teaching for at-risk students: Influences of a teaching experience in alternative high school. Journal of Instructional Psychology, 31(1), 46-52.

Franklin, W. (2000). Students at promise and resilient: A historical look at risk. In M. Sanders (Ed.), Schooling students placed at risk: Research, policy, and practice in the education of poor and minority adolescents (pp. 
3-16). Mahwah, NJ: Erlbaum.

Greene, R. (2002). Resilience: an integrated approach to practice, policy, and research (Washington, DC, NASW Press).

Hawley, D., \& DeHaan, L. (1996). Toward a definition of family resilience: integrating life-spanand family perspectives. Family Process, 35, 283-295. http://dx.doi.org/10.1111/j.1545-5300.1996.00283.x

Kralik, D. (2002). The quest for ordinariness: transition experienced by midlife women living with chronic illness, Journal of Advanced Nursing, 39(2), 146-154. http://dx.doi.org/10.1046/j.1365-2648.2000.02254.x

Kralik, D., van Loon, A., \& Visentin, K. (2006). Resilience in the chronic illness experience. Educational Action Research, 14(2), 187-201. http://dx.doi.org/10.1080/09650790600718035

Luthar, S., Cicchetti, D., \& Becker, B. (2000). The construct of resilience: A critical evaluation guidelines for future work. Child Development, 71, 543-562. http://dx.doi.org/10.1111/1467-8624.00164

Martinez, Y. J., \& Ercikan, K., (2009). Chronic illnesses in Canadian children: What is the effect of illness on academic achievement, and anxiety and emotional disorders? Child: Care, Health and Development, 35(3), 391-401. http://dx.doi.org/10.1111/j.1365-2214.2008.00916.x

Masten, A. (2001). Ordinary magic: resilience processes in development, American Psychologist, 56(3), 227-238. http://dx.doi.org/10.1037/0003-066X.56.3.227

Masten, A. (2003). Commentary: Developmental psychology as a unifying context for mental health and education models, research, and practice in schools. School Psychology Review, 32, 170-174.

Masten, A.S., \& Obradovic, J. (2006). Competence and resilience in development. Annals New York Academy of Sciences, 1094, 13-27. http://dx.doi.org/10.1196/annals.1376.003

McCabe, P. C., \& Shaw, S. R. (2008). Hospital-to-school transition for children with chronic illness: Meeting the new challenges of an evolving health care system. Psychology in the Schools, 45(1), 74-87. http://dx.doi.org/10.1002/pits.20280

Oswald, M., Johnson, B., \& Howard, S. (2003). Quantifying and evaluating resilience promoting factors: Teachers' beliefs and perceived roles. Research in Education, 70, 50-64.

Patterson, J. (1995). Promoting resilience in families experiencing stress, Pediatric Clinics of North America, 42, 47-63.

Polk, L. (1997). Toward a middle-range theory of resilience, Advances in Nursing Science, 19(3), 1-13.

Reis, S., Colbert, R., \& Hebert, T. (2005). Understanding resilience in diverse, talented students in an urban high school. Roeper Review, 27(2), 110-121. http://dx.doi.org/10.1080/02783190509554299

Shapiro, E. (2002). Chronic illness as a family process: A social-developmental approach to promoting resilience. Journal of Clinical Psychology, 58(11), 1375-1384. http://dx.doi.org/10.1002/jclp.10085

Stefkovich, J., \& Begley, P. T. (2007). Conceptualizing ethical school leadership and defining the best interests of students [Special issue]. Educational Management and Leadership, 35(2), 205-225. http://dx.doi.org/10.1177/1741143207075389

Thies, K. M. (1999). Identifying the educational implications of chronic illness in school children. Journal of School Health, 69(10), 392-397. http://dx.doi.org/10.1111/j.1746-1561.1999.tb06354.x

Thomsen, K. (2002). Building resilient students: Integrating resilience into what you already know and do. Thousand Oaks, CA: Corwin Press.

Wang, M., Haertel, G., \& Walberg, H. (1997). Fostering educational resilience in inner-city schools (Pub. No. 4). Philadelphia: National Research Center on Education in the Inner Cities.

Waxman, H., Gray, J., \& Padron, Y. (2004). Promoting educational resilience for students at risk of failure. In H. Waxman,Y. Padron, \& J. Gray (Eds.), Educational resiliency: Student, teacher, and school perspectives (pp. 37-62). Greenwich, CT: Information Age.

Wideman-Johnston, T. (2010). The academic journey of students with chronic gastrointestinal illness: Narratives from daughters and their mothers (Unpublished master's thesis).Nipissing University, North Bay, Ontario.

Worchel-Prevatt, F. F., Heffer, R. W., Prevatt, B. C., Miner, J., Young-Saleme, T., \& Horgan, D., et al. (1998). A school reentry program for chronically ill children. Journal of School Psychology, 36(3), 261-279. http://dx.doi.org/10.1016/S0022-4405(98)00012-0 